\title{
Durability of self-adhesive tapes for exterior air barrier applications:
}

\author{
a laboratory investigation
}

\author{
Jelle Langmans ${ }^{1 \star}$, Tadiwos Zerihun Desta ${ }^{2}$, Lieven Alderweireldt ${ }^{2}$, Staf Roels ${ }^{1}$ \\ ${ }^{1}$ Department of Civil Engineering, Building Physics Section, KU Leuven, University of Leuven \\ Kasteelpark Arenberg 40 - bus 02447, BE-3001 Heverlee, Belgium \\ ${ }^{2}$ Redco nv \\ Kuiermansstraat 1, B-1880 Kapelle-op-den-Bos, Belgium
}

* Corresponding author. Tel: +32 16 321349; fax: + 3216321980 .

E-mail address: jelle.langmans@bwk.kuleuven.be (J. Langmans)

\begin{abstract}
In timber frame construction in Europe air barrier systems are typically realised at the interior side of the building envelope. Yet in some applications such as renovation projects it can be easier to provide the air barrier layer at the exterior. An exterior air barrier system, typically board materials in which the joints are sealed with tape, need to withstand severe outdoor weather conditions and maintain predefined air permeability values. The aim of the present article is to investigate the impact of severe climatic conditions on the airtightness of typical taped joints. The airtightness of thirty-two wood-fibre cement board samples has been investigated. Each specimen has a $2 \mathrm{~mm}$ wide joint. Two different kinds of commercially available tapes were used to seal these joints. Airtightness of all specimens has been tested before and after accelerated ageing procedures that mimics real exterior climate conditions. Three different ageing protocols were selected: 1) temperature cycles, 2) temperature, rain and frost cycles and 3) UV exposure alternate with high humid conditions. For the first two test conditions, the specimens had a size of 0.71 by $0.71 \mathrm{~m}^{2}$. Due to sample size restrictions of the UV exposure cabin, the specimens of the third test run were smaller $(0.35 \mathrm{~m}$ by $0.35 \mathrm{~m})$. All specimens had a thickness of $12 \mathrm{~mm}$. The present paper discusses the durability of the two tapes by comparing the air permeability of the specimens before and after accelerated ageing exposure.

The results indicate that for both tapes tested the impact of the three artificial ageing methods on the air permeability is limited (increment less than $2 \times 10^{-5} \mathrm{~m}^{3} / \mathrm{m} / \mathrm{h} / \mathrm{Pa}$ ).
\end{abstract}

Keywords: taped joints, frost, temperature and humidity cycles, exterior air barrier, UV exposure

\section{Introduction}

Robust air barrier systems are one of the prerequisites to achieve energy efficient buildings. In light weight construction in Europe, the air barrier layer is commonly positioned close to the interior finish. This layer often also incorporates the vapour barrier functionality. Contrary to the popular practice, in some projects (e.g. renovations) it can be easier, practical and faster to position the air barrier layer at the exterior side of the building envelope. Figure 1 shows two projects in which such an exterior 
barrier is successfully applied. The left hand side picture illustrates this technique for a single family house (Langmans et al. 2010). It was shown that the approach resulted in reduction of labour cost up to $60 \%$ when compared with air barrier systems at the interior (Langmans, 2013). The right hand side picture illustrates an example of an energetic renovation project at the University of Leuven (KU Leuven) in which a concrete office building is enclosed with prefabricated elements (Tijskens, 2015). By applying an exterior air barrier in this project the air barrier layer is realised in one continuous plane. As a consequence the cost for improving the airtightness in this project could be highly reduced in comparison to a traditional interior air barrier. However, realising an exterior air barrier implicates that the taped joints are exposed to outside environmental conditions. Especially during the construction phase when the air barrier layer gets the least protection, these taped joints need to withstand high levels of temperature, humidity and UV radiation.
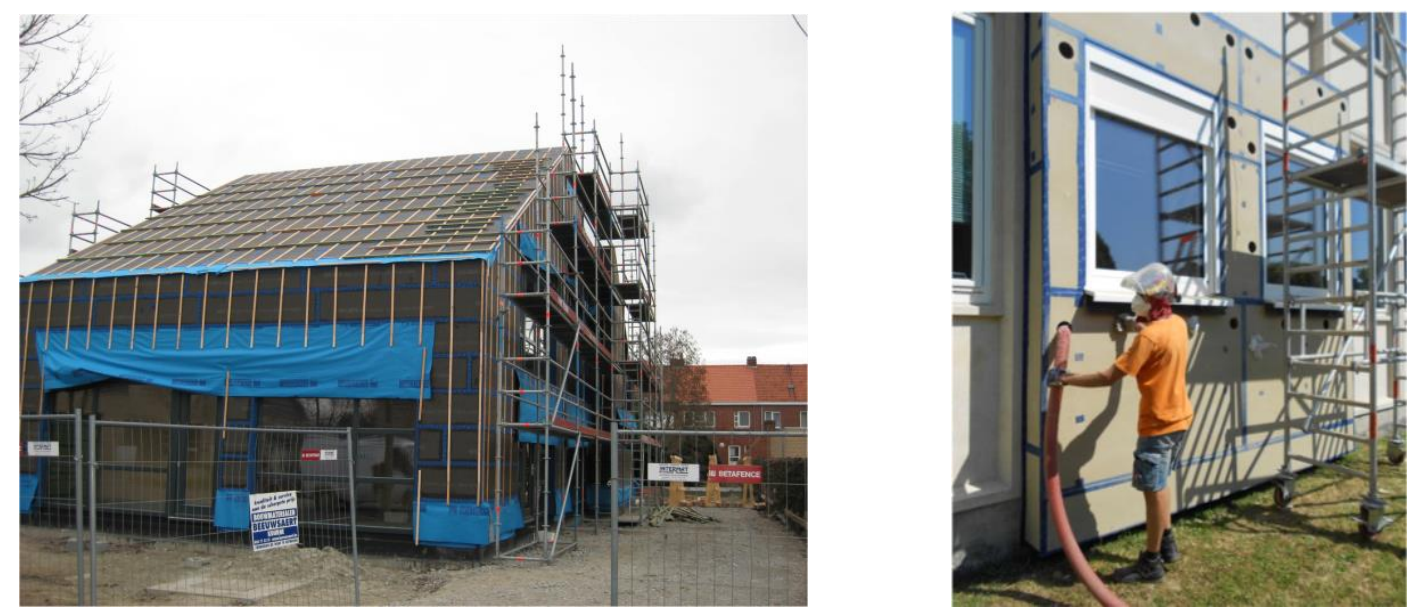

Figure 1: Left) Timber frame dwelling with exterior air barrier (Langmans et al. 2010) and right) low energy renovation of concrete office building with prefabricated timber frame elements with an exterior air barrier.

The available international literature regarding building airtightness durability is very limited. Few studies report variations in the global building airtightness within a time interval of several months or years. Bracke et al. (2013) showed a reasonably stable overall air leakage level for buildings with a high level of airtightness. In contrast, others reported significant deviations from the original value with the building ages (Hansén, 2012), or seasons (Borsboom and de Gids (2012) and Kim et al. (1986)). However, these studies evaluated the global building airtightness and do not provide detailed information regarding the key parameters influencing airtightness durability. To the authors knowledge only two studies have been investigating the durability of self-adhesive tapes used for building 
airtightness applications. Both Ackermann (2012) and Gross \& Maas (2011) developed a method based on the $180^{\circ}$ peel test according to BS EN 1939:19971. This standard is used to investigate the peel adhesion of self-adhesive tapes. The prepared specimens are loaded into a tensile testing machine in which the tape is peeled from the substrate in a $180^{\circ}$ direction. This test essentially provides information on the adhesion strength of the taped connection.

Gross \& Maas (2011) studied the peel force for several tapes and substrate materials (foils, wood and fibre cement boards). Before the peel test, artificial ageing of the specimen was established by preconditioning the samples at a temperature of $65^{\circ} \mathrm{C}$ and $80 \%$ relative humidity. Their results clearly show that the level of peel force depends on the substrate and the curing time of the adhesive. Moreover it is shown that the stress resistance of the adhesives in combination with a PE foil is significantly lower than with other bonding materials. Gross \& Maas (2011) also showed that solventfree adhesives correspond to higher values in peel force. In addition, the authors remarkably noted that with progressive accelerated ageing, the majority of the adhesives analysed show an increased peel force.

The second study in this kind was performed by Ackermann $(2007,2012)$ at FIW in Munich. Similar to Gross \& Maas (2011), Ackermann (2012) conditioned the samples before the peel test at a temperature of $65^{\circ} \mathrm{C}$ and $80 \%$ relative humidity. The impact of $21,40,80$ and 120 days preconditioning on the adhesive strength was investigated. Instead of a static peel test, he developed a method which allows alternating the loads in order to imitate the dynamic wind conditions. Yet his paper mainly focusses on the development of the test method rather than on the research findings.

The results of the abovementioned studies are highly dependent on the applied artificial ageing protocol. Both, Gross \& Maas (2011) and Ackermann (2012), expose the specimens to a temperature of $65^{\circ} \mathrm{C}$ in combination with $80 \%$ relative humidity which is based on ASTM D 3611-89 standard. This standard was originally established to assess the artificial ageing of tapes used in packaging applications. Yet, it can be questioned whether this protocol is representative for exterior applications where rain, frost and UV exposures can play a role in the ageing process.

An overview of artificial ageing methods for exterior conditions and building product properties to be tested before, during and after ageing is listed by (Jelle, 2012). The review puts great emphasis on

\footnotetext{
${ }^{1}$ BS EN 1939:1997 self-adhesive tapes - Measurements of peel adhesion from stainless steel or from its own backing
} 
the description of the Nordtest method NT Build 495. This Scandinavian test method recommends to expose materials and components used in the building envelope to UV light, heat, water and frost. Samples are subjected to four different conditions in a row: a) UV and IR irradiation zone (black panel temperature of $\left.63^{\circ} \mathrm{C}\right)$, b) water spray zone $\left(15 \mathrm{l} /\left(\mathrm{m}^{2} \mathrm{~h}\right)\right) \mathrm{c}$ ) freezing conditions $\left(-20^{\circ} \mathrm{C}\right)$ and $\left.\mathrm{d}\right)$ thawing at laboratory conditions. According to Nordtest NT Build 495 the exposure time to each condition is at least one hour in the above given sequence but the document does not specify the exact duration of the test.

Other standards regarding weathering and accelerated climate ageing mentioned by (Jelle, 2012) are e.g. ASTM G23-81, ASTM G24-87, ASTM G26-84, ASTM G53-84, EN 927-3, EN 927-6 [26], EN 1296 which all target ageing of building applications in exterior conditions. These standards range from assessing the ageing of paints, flexible sheets, water proofing products to wood coatings. The standard from the European Technical Approval Guidelines, ETAG 004 (2009) is not mentioned in the review article of Jelle (2012). However, this technical approval which is widely used to assess the durability of external thermal insulation composite systems (ETICS), describes a specific hygrothermal accelerated ageing protocol and can be adopted and used to assess durability of taped joints in exterior applications. According to ETAG 004, the samples are first exposed to 80 heat-rain cycles (each cycle with 3 hours heating at $70^{\circ} \mathrm{C}, 1$ hour rain with $1 \mathrm{l} / \mathrm{m}^{2} \mathrm{~min}$, and 2 hour rest). Thereafter five frost/thaw cycles are imposed (each cycle with 8 hours at $50^{\circ} \mathrm{C}$ followed by 16 hours of freezing at $\left.-20^{\circ} \mathrm{C}\right)$.

Though there have been attempts to correlate some of the above mentioned artificial ageing protocols with natural ageing (e.g. Ackermann, 2012) it remains very difficult and even unlikely to mimic natural ageing in laboratory conditions. As a consequence, even comparing the results of test with different ageing protocols is not straightforward.

In summary it can be stated that the available literature on the durability of air barrier sealing products is very limited. The only information currently available is related to the relation of static artificial ageing tests on the peel force of the sealing (Gross \& Maas, 2011), (Ackermann, 2012). The applied methods are based on standardised peel tests, and thus, provide only information on the adhesive strength of the connection. These methods can be applied to compare the adhesion durability of different kinds of taped joints. However the outcome of such tests does not provide information on the 
impact of the artificial ageing on the air permeability of the taped connection. In addition, the existing research on the durability of self-adhesive air barrier tapes is limited to ageing by temperature and relative humidity $(<80 \%)$ cycles (ASTM D 3611-89). These conditions can be representative for interior conditions, however, for the present scope of exterior applications the method is insufficient as it neglects effects of rain, UV light, high relative humidity (>80\%) and frost exposures.

The aim of the present study is to investigate the impact of weather conditions on the actual air permeability of taped joints in exterior applications. Samples with a taped joint will be tested before and after severe artificial ageing exposures. The study explores the behaviour of two different types of tapes on a wood fibre cement board substrate. Herein three different artificial ageing methods to mimic exterior conditions will be applied: a) thermal loads, b) hygrothermal loads and c) combined UV and vapour loads.

\section{Test setup and methodology}

The air permeability of in total thirty two samples with taped joints is measured before and after conditioning. Two different tapes, two spacing materials and three different sample conditioning schemes are investigated. The following sections describe the applied materials, the conditioning schemes and the air permeability measurement apparatus.

\subsection{Test materials and samples}

The tests are performed on medium density wood-fibre boards ${ }^{2}$ with taped joints (e.g. applied as exterior air barrier layer in the right hand side picture in Figure 1). These boards are composed of a coarse core, faced on each side with a fine smooth top layer (Figure 2). The board is made of mainly Portland cement, water and wood fibres.

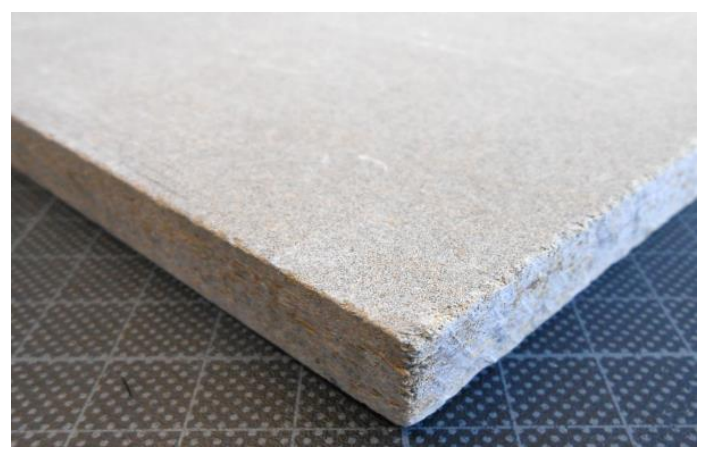

Figure 2: Cross-section of the used medium density cement/wood fibre boards.

\footnotetext{
${ }^{2}$ Duripanel of Eternit
} 
The test samples are either 0.71 by $0.71 \mathrm{~m}^{2}$ or 0.35 by $0.35 \mathrm{~m}^{2}$ depending on the sample conditioning (see section 2.2). Figure 3 illustrates that each specimen consists out of two parts which are connected with two spacers leaving a joint of $2 \mathrm{~mm}$ in between. Two different spacer materials are used: a) aluminium and b) wood. Aluminium and wood are chosen as a spacer because of their different thermal and hygric expansion coefficients. This will induce different stress on the tapes during the sample conditioning (see section 2.2). Typical studs spacing in timber frame construction is 50-60 cm which is in line with the distance between the fixations points of the spacers of the biggest samples $(59 \mathrm{~cm})$.
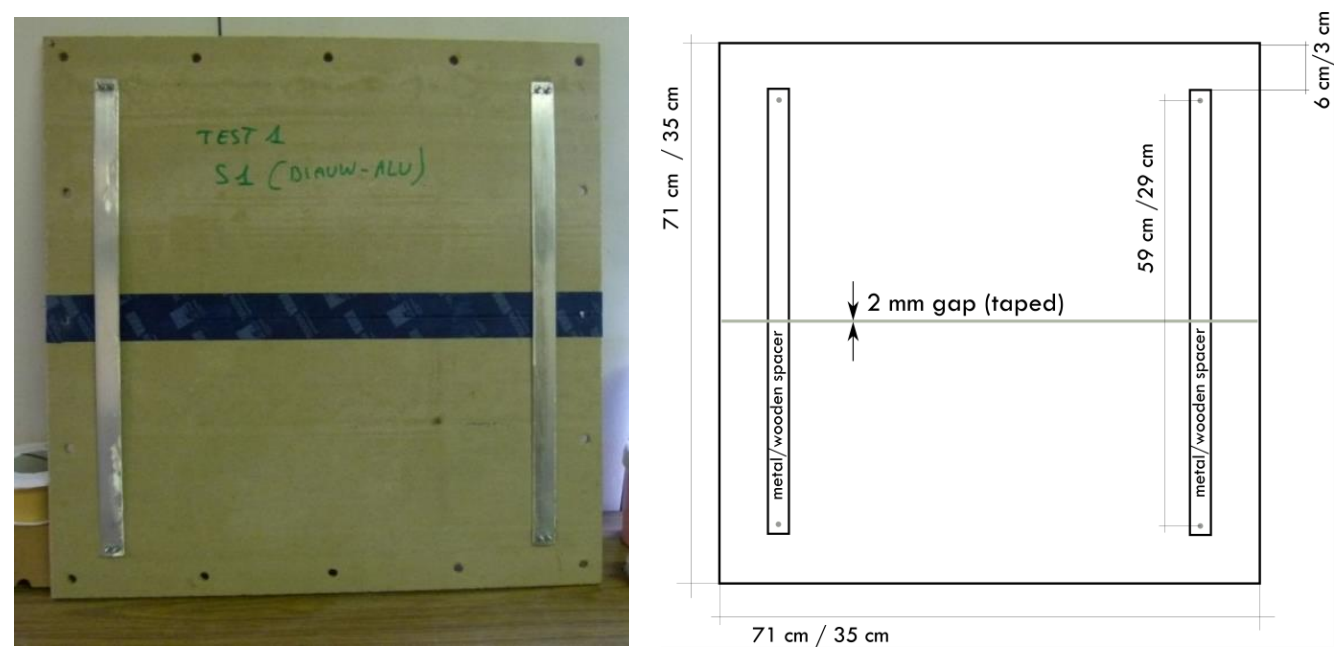

Figure 3: Test samples: left) sample of 0.71 by $0.71 \mathrm{~m}^{2}$ with aluminium spacer and right) dimensions for the big/small samples.

The tests are performed for two different commercially available airtightness tapes: Tape $A^{3}$ and Tape $B^{4}$. Table 1 summarizes the sample configurations. Next section will outline the conditions to which these samples are exposed.

Table 1: Summary of the samples.

\begin{tabular}{|c|c|c|c|c|}
\hline \multirow[b]{2}{*}{$\begin{array}{l}\text { SAMPLE } \\
\text { SERIES }\end{array}$} & \multirow[b]{2}{*}{ Tape } & \multirow[b]{2}{*}{ Spacer } & \multicolumn{2}{|c|}{ Number of samples } \\
\hline & & & $\begin{array}{c}\text { Big samples } \\
\left(0.71 \times 0.71 \mathrm{~m}^{2}\right)\end{array}$ & $\begin{array}{l}\text { Small samples } \\
\left(0.35 \times 0.35 \mathrm{~m}^{2}\right.\end{array}$ \\
\hline I & Tape A & Aluminium & 6 & 2 \\
\hline II & Tape B & Aluminium & 6 & 2 \\
\hline III & Tape A & Wood & 6 & 2 \\
\hline
\end{tabular}




\subsection{Sample conditioning}

Several existing weathering methods have been briefly discussed in the introduction section. The aim of the present paper is to investigate the durability of self-advise tapes for exterior air barrier applications. This means that the taped joints will only be exposed to full exterior conditions during the construction phase. From the moment the cladding/roof systems are installed, the joints are partially protected from the extreme conditions. This implies that the ageing conditions need to mimic exterior conditions partially and thus the method applied by Ackermann (2012) and Gross \& Maas (2011) based ASTM D 3611-89 is insufficient for the current application. On the other hand, applying test methods designed for elements directly exposed to outer conditions for the entire service life such ETAG 004 and Nordtest method NT Build 495 are most probably too severe. Having this in mind, three compromise test programs are proposed. The first test program was limited to thermal cycles. This program has been designed to mimic levels of thermal movements which are expected in in-situ conditions. The second program included heat, rain and frost cycles. However, as the self-adhesive taped joints in the application are partially protected when the building is finished, only half of the standard weathering protocol for outdoor conditions (ETAG 004 cycles) are considered. Finally, in the third test program, the samples have been exposed to UV and vapour conditions in line with ASTM G154. The following sections outline the three separate weathering protocols in detail.

\subsubsection{Test 1: Temperature cycles}

Three big samples $\left(0.71 \times 0.71 \mathrm{~m}^{2}\right)$ from each of the I to IV sample series (12 samples in total) are exposed to temperature cycles at $30 \%$ relative humidity (sample series are described in Table 1).The aim of this conditioning scheme is to expose the samples to high temperature differences. For two weeks cycles of 24 hours at $70^{\circ} \mathrm{C}$ are followed by 24 hours at $15^{\circ} \mathrm{C}$. In this test protocol, the taped joints are exposed to both thermal and mechanical stresses. The latter is induced by the thermal expansion of the spacer which is only fixed at the end points. For aluminium, which has a thermal expansion coefficient of $23.2 \times 10^{-6} \mathrm{~m} / \mathrm{m} / \mathrm{K}$ this corresponds to a displacement of $0.74 \mathrm{~mm}$ which is 
equivalent to the thermal movement of the wood-cement board. For the wooden spacer with a thermal expansion coefficient of $5 \times 10^{-6} \mathrm{~m} / \mathrm{m} / \mathrm{K}$ this is only $0.2 \mathrm{~mm}$.

\subsubsection{Test 2: Temperature, rain and frost cycles}

Similar to test 1, three big samples from each samples series (12 samples in total) are used in test 2.

This conditioning scheme increases the load by subjecting the samples to water and freezing conditions on top of the exposure to elevated temperatures. First the samples are exposed to 40 heatrain cycles $\left(3\right.$ hours heating at $70^{\circ} \mathrm{C}$ and $10-30 \% \mathrm{RH}, 1$ hour rain with $1 \mathrm{l} / \mathrm{m}^{2} / \mathrm{min}$ at $15^{\circ} \mathrm{C}$ and 2 hour rest). Thereafter two frost cycles are imposed $\left(8\right.$ hours at $50^{\circ} \mathrm{C}$ followed by 16 hours of freezing at $-20^{\circ} \mathrm{C}$ ). This scheme corresponds to half of the normal hygrothermal cycles of ETAG004 ${ }^{5}$. Figure 4 illustrates the preparation of the test samples on the test rig before they are positioned in the climatic chamber. It shows that 12 samples have been installed together and that the joints between the samples have been sealed with aluminium tape to prevent moisture ingress through the edges.

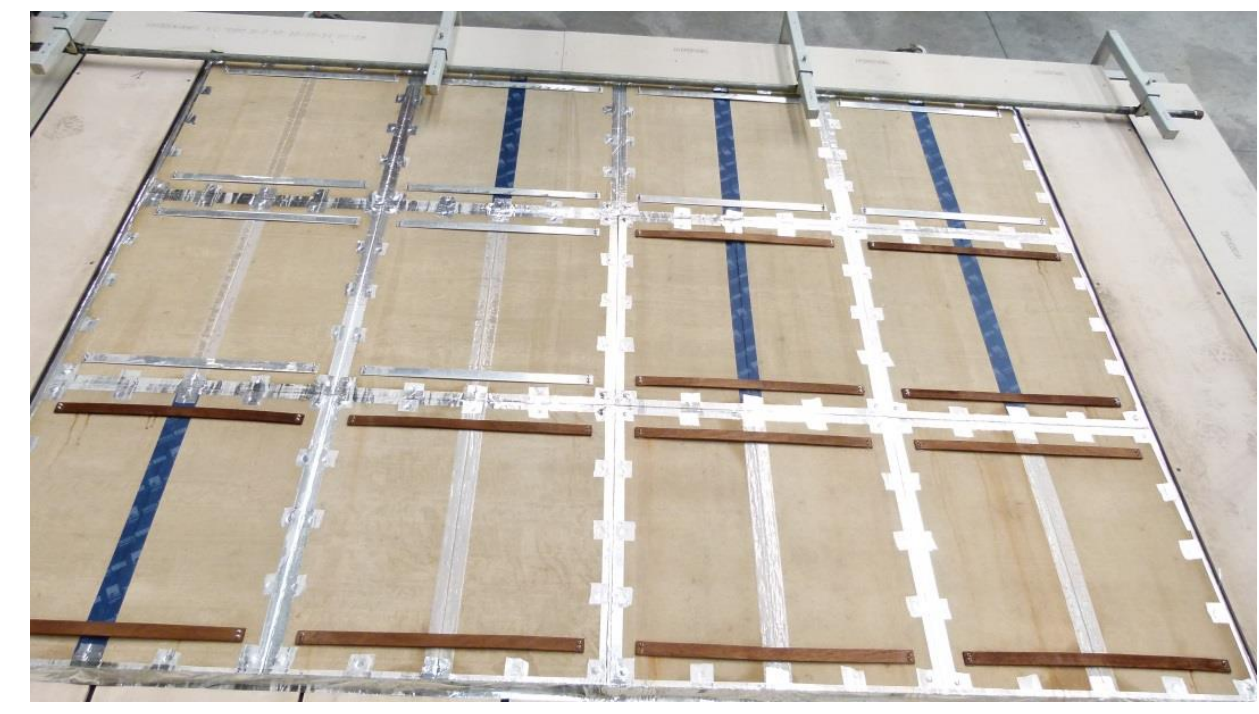

Figure 4: Preparation of test samples for test 2.

\subsubsection{Test 3: UV-light cycles}

During the construction phase exterior air barrier tapes will, in addition to hygrothermal loads, be exposed to solar radiation. This is often combined or alternated with periods of high moisture contents due to rain or condensation on the building envelopes surface. These conditions are simulated in the

\footnotetext{
${ }^{5}$ Guideline for European technical approval of external thermal insulation composite systems with rendering.
} 
third conditioning scheme in which the samples are exposed to UV-light alternated with periods of vapour exposure based on ASTM G-154 $4^{6}$. Herein the samples are exposed to 56 cycles of 8 hours UV-exposure $\left(40^{\circ} \mathrm{C}\right)$ followed by 4 hours of vapour exposure $\left(60^{\circ} \mathrm{C}\right)$. The UV-light is transmitted by a UVB-313EL lamp corresponding to wavelengths between $280-400 \mathrm{~nm}$ and an intensity of 0.7 $\mathrm{W} / \mathrm{m}^{2} / \mathrm{nm}$. Two small samples $\left(0.35 \times 0.35 \mathrm{~m}^{2}\right)$ from each of the I to IV sample series (in total 8 samples) were used in the test.

All the three accelerated climatic exposures are summarised in Figure 5 and Table 2.
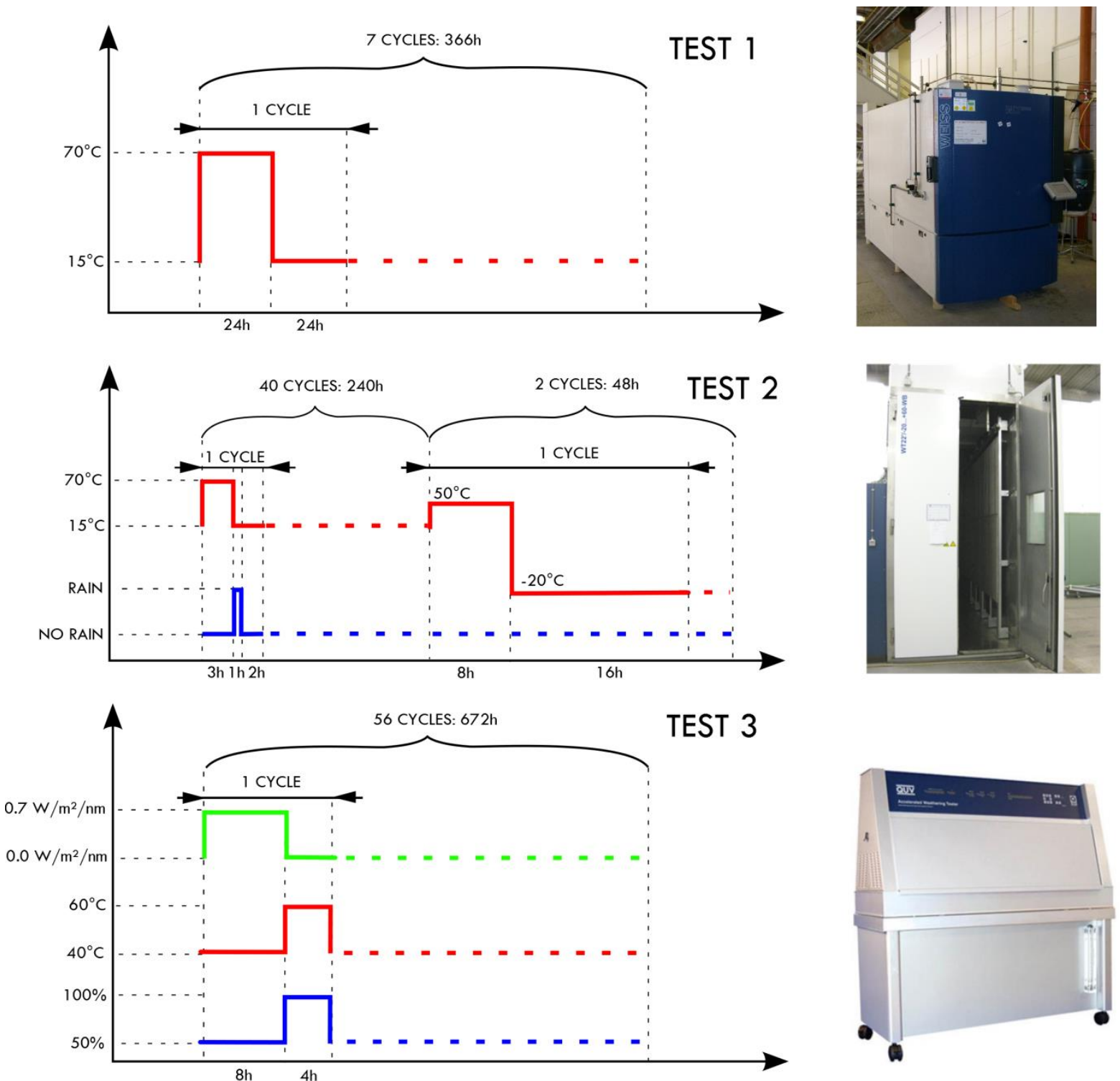

Figure 5: Overview of 3 test protocols and picture of corresponding climatic chamber.

\footnotetext{
${ }^{6}$ Operating Fluorescent Light Apparatus for UV Exposure for Nonmetallic Materials

${ }^{7}$ QUV weathering tester (Q-lab)
} 
Table 2: Summary of the accelerated ageing programme.

\begin{tabular}{|c|c|c|c|}
\hline Test series & Type & Total time & Conditions \\
\hline TEST 1 & Temperature & 14 days & $6 \times\left(24 \mathrm{~h} 70^{\circ} \mathrm{C}\right.$ and $24 \mathrm{~h} 15^{\circ} \mathrm{C}$ at $\left.30 \% \mathrm{RH}\right)$ \\
\hline TEST 2 & Temperature, rain, frost & 12 days & $\begin{array}{c}40 \times\left(3 \mathrm{~h} 70^{\circ} \mathrm{C} \text { at } 10-30 \% \mathrm{RH}-1 \mathrm{~h} \text { rain with } 1 \mathrm{l} / \mathrm{m}^{2} / \mathrm{min}\right. \\
\left.\text { at } 15^{\circ} \mathrm{C}-2 \mathrm{~h} \text { repose }\right)- \\
2 \times\left(8 \mathrm{~h} 50^{\circ} \mathrm{C}-16 \mathrm{~h}-20^{\circ} \mathrm{C}\right)\end{array}$ \\
\hline TEST 3 & UV-exposure, vapour & 4 weeks & $56 \times\left(8 \mathrm{~h}\right.$ UV $\left(40^{\circ} \mathrm{C}\right)$ and $4 \mathrm{~h}$ vapour exposure $\left.\left(60^{\circ} \mathrm{C}\right)\right)$ \\
\hline
\end{tabular}

\subsection{Air permeability test-setup}

The air permeability of the samples is measured in laboratory conditions $\left(20^{\circ} \mathrm{C}, 50 \% \mathrm{RH}\right)$ both before and after the sample conditioning. Two similar test-setups have been applied for these measurements. The first test setup was designed to measure the air permeability of the samples with a dimension of 0.71 by $0.71 \mathrm{~m}^{2}$. This set up is used to measure the air permeability of samples aged in TEST 1 and TEST 2 (see Table 2). In addition, a smaller box with a test frame of 0.35 by $0.35 \mathrm{~m}^{2}$ is used to measure the air permeability of the samples which were exposed to the UV-light in TEST 3. Both setups, which are designed according to the EN12114 standard, consist of a metal frame box open at one side to install the specimen to be measured (Figure 6).

To avoid unwanted air leakages through the perimeter joints between the specimen and the airtight boxes, closed cell EPDM with a thickness of $2 \mathrm{~cm}$ on both sides of the specimen have been used to seal the specimen airtight with a metal frame against the airtight box. 


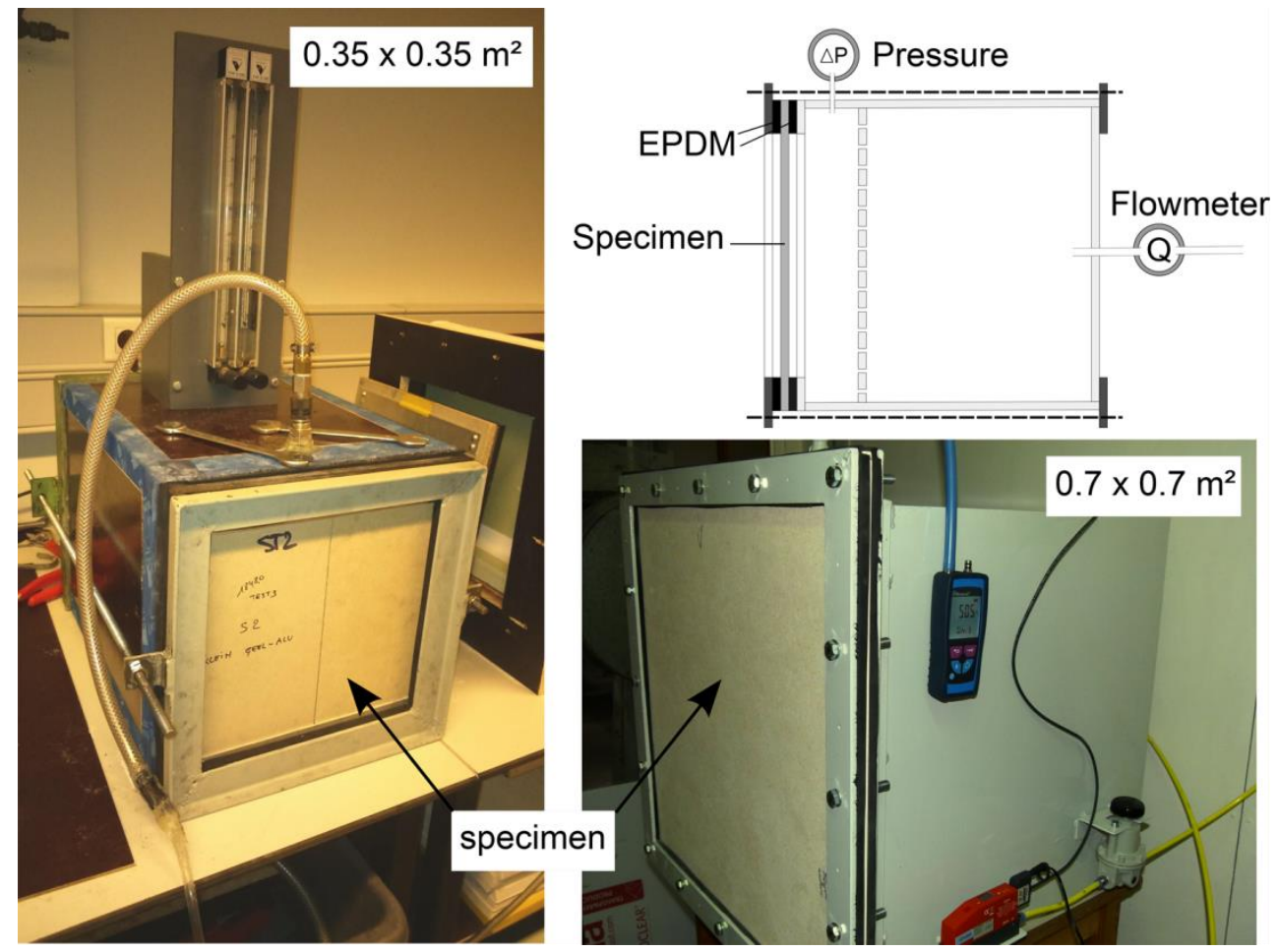

Figure 6: Laboratory test set-up to measure air permeability of building materials.

After installing the specimen on the airtight box, compressed air was introduced and over-pressure was created in the box. This resulted in air flow through the specimen. By stepwise increasing the pressure difference across the specimen and measuring the corresponding air flow rate and differential pressure across the specimen a data set was obtained. The airflow $g_{a}\left(m^{3} / m^{2} / h\right)$ can be expressed as an air permeance $\mathrm{K}_{\mathrm{a}}$ multiplied by the pressure drop across the specimen $\Delta \mathrm{Pa}$ (Hens 2007):

$$
g_{a}=K_{a} \Delta P_{a}
$$

The construction junctions are assumed to be a parallel circuit of air resistances. Hereby, the air permeance of a joint $\mathrm{K}_{\text {joint }}\left(\mathrm{m}^{3} / \mathrm{m} / \mathrm{h} / \mathrm{Pa}\right)$ can be deduced from the measured air permeance of the specimen with joints $\mathrm{K}_{\text {spec }}$, given that the air permeance of the material (without joints, one piece) $\mathrm{K}_{\text {mat }}$ $\left(\mathrm{m}^{3} / \mathrm{m}^{2} / \mathrm{h} / \mathrm{Pa}\right)$ is known from the small test-setup (Hens, 2006):

$$
K_{\text {joint }}=\frac{\left(K_{\text {spec }}-K_{\text {mat }}\right) \cdot A_{\text {spec }}}{l_{\text {joint }}}
$$


For the small test setup a pressure gauge 4 DG-700, with an accuracy of $1 \%$ was applied. The flow rate was determined with a Vögtlin variable area flow meter. In a range from $0.02 \mathrm{~m} 3 / \mathrm{h}$ to $0.90 \mathrm{~m}^{3} / \mathrm{h}$ the flow rate could be measured with an accuracy of $2 \%$. The overall leakage of the test setup itself, including the ductwork connections, was estimated to be $0.0035 \mathrm{~m}^{3} / \mathrm{h}$ at $50 \mathrm{~Pa}$. For the bigger testsetup a BlueLine S2600 pressure transducer with an accuracy of $1 \%$ was used. Here a digital flowmeter (Vögtlin GSM-C) with a measuring range from $0 \mathrm{~m}^{3} / \mathrm{h}$ to $0.36 \mathrm{~m}^{3} / \mathrm{h}$ and an accuracy of $0.3 \%$ was applied. The leakage of the bigger apparatus was $0.0032 \mathrm{~m}^{3} / \mathrm{h}$ at $50 \mathrm{~Pa}$.

\section{Test results}

This section discusses the measuring results. First, the air permeability of the board material and the taped joints before the ageing procedure will be outlined. Thereafter the impact of the 3 artificial ageing tests on the specimen's air permeability will be presented.

\subsection{Air permeability of the board and taped joints}

First the air permeability of the $12 \mathrm{~mm}$ thick wood fibre cement board is measured on specimen without joints. This air permeability of the boards $\left(1.04 \times 10^{-4} \mathrm{~m}^{3} / \mathrm{m}^{2} / \mathrm{h} / \mathrm{Pa}\right)$ is then subtracted from the air permeability of the specimen with taped joints in the same test-setup before the artificial ageing. The results reveal that the air permeability of the taped joints is very low; $3.110^{-6} \mathrm{~m} / \mathrm{m} / \mathrm{h} / \mathrm{Pa}$ for Tape A and $3.910^{-7} \mathrm{~m}^{3} / \mathrm{m} / \mathrm{h} / \mathrm{Pa}$ for Tape B.

\subsection{Impact of artificial ageing on air permeability of the taped joints}

The previous section showed that the air permeability of the taped joints is very low before the samples are exposed to artificial ageing for both tapes. This section investigates the impact of the 3 accelerated ageing protocols on the joints air permeability. Figure 7 plots the difference between the air permeability before and after the artificial ageing test. The bars in the figure correspond to the averaged values and the limits are the minimum and maximum value. 


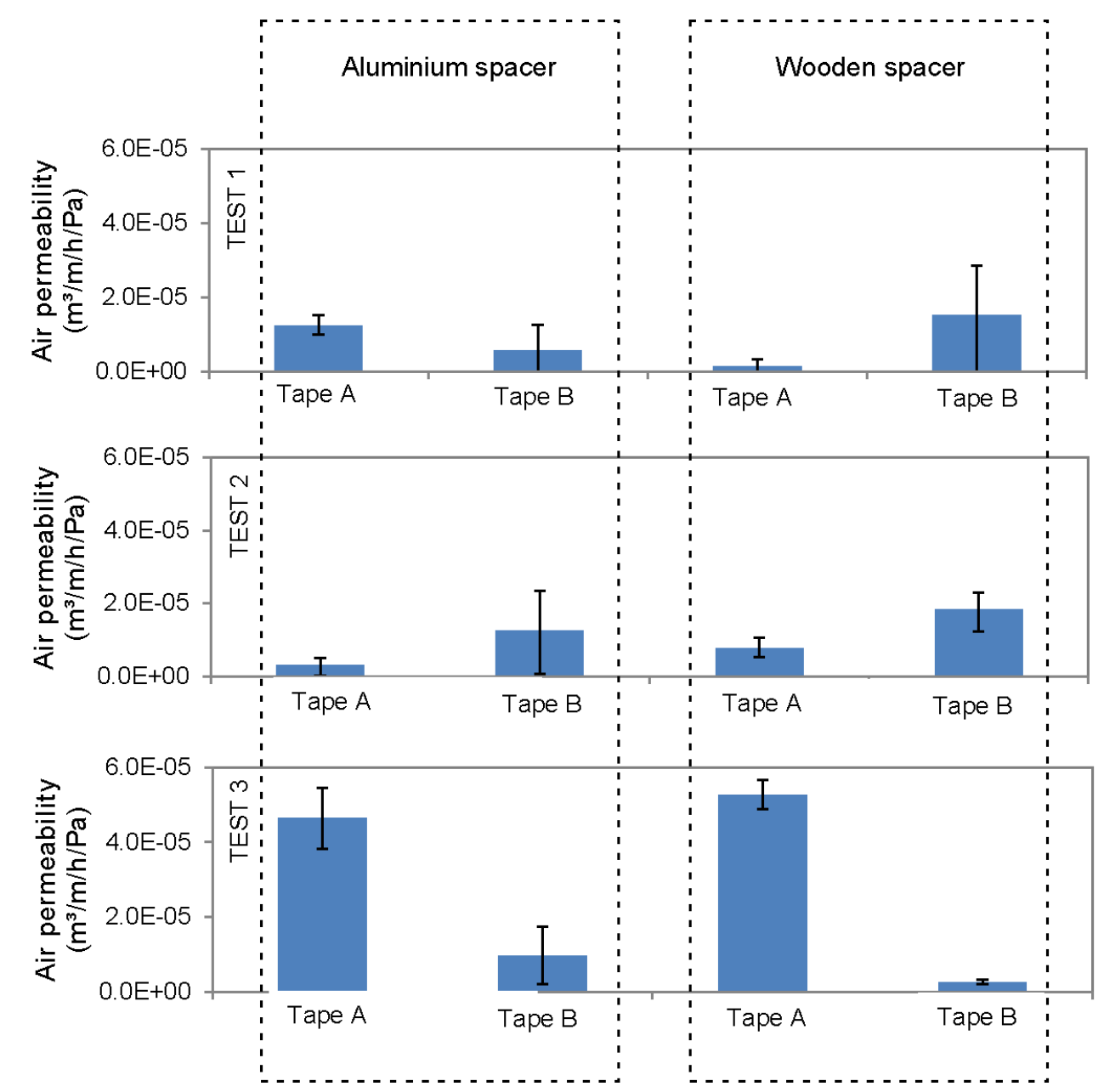

Figure 7: Increase in air permeability of the joints after the artificial ageing of the samples.

The results indicate that the increase in air permeability is limited to $210^{-5} \mathrm{~m}^{3} / \mathrm{m} / \mathrm{h} / \mathrm{Pa}$ for the first two ageing procedures. Even though the second procedure is much more severe with rain and frost cycles, the impact on the permeability remains comparable with the first procedure. Moreover neither significant differences between the different spacing methods nor the different tapes are noticed. For the third ageing protocol, in contrast, Tape B seems to perform better than Tape A. However, it should be noted that the increase of the air permeability is limited to $4-610^{-5} \mathrm{~m} / \mathrm{m} / \mathrm{h} / \mathrm{Pa}$ which is still very low.

\section{Discussion and Conclusions}

In contrast to traditional interior barriers, exterior air barrier systems can be exposed to severe weather conditions. These outdoor conditions may have an impact on the durability of sealed connections. The article at hand proposes a novel methodology to study the durability of self-adhesive taped joints based on air permeability measurements before and after accelerated ageing exposures. In this study two different commercially available tapes are evaluated. The accelerated ageing 
protocols range from a) temperature cycles, b) temperature, rain, frost cycles (based on ETAG 004) up to c) UV and vapour exposure (based on ASTM G-154-12a). The novelty of the present article lies in that the change in the joint's air permeability was directly quantified by measuring the specimen's air permeability before and after carefully planned accelerated ageing protocols which are close to expected 'real life' outside conditions. So far the durability of self-adhesive tapes was only measured indirectly by standard peel tests according to BS EN 1939:1997. (e.g. Ackermann (2012) and Gross \& Maas (2011)). Moreover the ageing procedures in these two reports were less severe than the conditions tapes in exterior applications may encounter.

The results reveal that the permeability increase is limited for both tapes. For the temperature, rain and frost cycles the increment stayed below $2 \times 10^{-5} \mathrm{~m}^{3} / \mathrm{m} / \mathrm{h} / \mathrm{Pa}$. For the UV and vapour cycles a slightly higher impact was noticed for Tape A $\left(4-6 \times 10^{-5} \mathrm{~m} / \mathrm{m} / \mathrm{h} / \mathrm{Pa}\right)$. Yet it should be stressed that this increase is still very small. To get an idea of the order of magnitude this increase in permeability can be translated to a share of the overall $n_{50}$-value of a building. Langmans et al. (2010) studied the airtightness of a detached house with an exterior air barrier (left hand side picture in Figure 1). The total length of the joints in the exterior layer was $1280 \mathrm{~m}$ and the volume of the building was $1083 \mathrm{~m}^{3}$. For this case study an increase of the air permeability of $610^{-5} \mathrm{~m}^{3} / \mathrm{m} / \mathrm{h} / \mathrm{Pa}$ would correspond to an increase of the $n_{50}$-value of only $0.0031 / h$. This is two orders of magnitude smaller than the threshold value applied in the Passive house standard $(0.61 / \mathrm{h})$.

The air permeability tests in the present research have been executed under static pressure conditions. Though the air pressure differences are higher during the tests than in typical building application (300-1000 Pa), they do not mimic dynamic wind effects which will occur in practise.

Further it should be stressed that the present article is limited to taped joints which are installed in perfect conditions. Further research to investigate the influence of the weather impact on the durability of imperfectly taped joints is recommended. Suggested parameters to investigate in future research are the pressure applied on the tape during installation, effects of dusty and damp surfaces and the use of primers. Furthermore the use of different kind of board-tape combination and incorporation of statistical analysis with increased sample size per test are recommended.

\footnotetext{
${ }^{8}$ BS EN 1939:1997 self-adhesive tapes - Measurements of peel adhesion from stainless steel or from its own backing
} 


\section{Acknowledgements}

Research funded by a Postdoctoral Innovation Mandate (grant number 140695) of the Institute for the Promotion of Innovation through Science and Technology in Flanders (IWT-Vlaanderen).

\section{References}

Ackermann, T. (2007). "Untersuchungsergebnisse zur Dauerhaftigkeit von Verbindungen und Anschlüssen bei Luftdichtheitsschichten mittels Klebemassen und Klebebändern". Proceedings of the European Blowerdoor symposium, Kassel, Germany 109-119.

Ackermann, T. (2012). "Alternating loads - a method for testing the durability of adhesives in air tightness layers". Proceedings of the AIVC-TightVent international workshop, Brussels, Belgium. 6166 .

ASTM G-154-12a (2012). "Operating Fluorescent Light Apparatus for UV Exposure for Non-metallic Materials”, ASTM International, West Conshohocken, PA.

ASTM D 3611-89 (1998). "American Society for Testing Material "Standard Practice of Accelerated Aging of Pressure-Sensitive Tapes" Designation, ASTM International, West Conshohocken, PA.

ASTM G23-81 (1981). "Standard practice for operating light exposure apparatus (carbon-arc type) with and without water for exposure of non-metallic materials", ASTM International, West Conshohocken, PA, 699.

ASTM G24-87 (1987). "Standard practice for Conducting exposures to daylight filtered through glass", ASTM International, West Conshohocken, PA, 852.

ASTM G26-84 (1984). "Standard practice for operating lightexposure apparatus (xenon-arc type) with and without water for exposure of non-metallic materials", ASTM International, West Conshohocken, PA, 706-713.

ASTM G53-84 (1984). "Standard practice for operating light- and water-exposure apparatus (fluorescent UV-condensation type) for exposure of non-metallic materials", ASTM International, West Conshohocken, PA, pp 714.

Bracke W., Laverge J., Van den Bossche N., Janssens A., (2016), Durability and measurement uncertainty of airtightness in extremely airtight dwellings, International journal of ventilation. 14(4). pp.383-394

Borsboom, W. and de Gids, W. 2012. "Seasonal variation of facade airtightness: field observations and potential impact in NZEB". Proceedings of the AIVC-TightVent international workshop, Brussels, Belgium. 77-84.

EN 927-3 (2000). "Paints and varnishes. Coating materials and coating systems for exterior wood. Part 3: natural weathering test".

EN 927-6 (2006). "Paints and varnishes. Coating materials and coating systems for exterior wood. Part 6: exposure of wood coatings to artificial weathering using fluorescent UV lamps and water". 
EN 1296 (2001). "Flexible sheets for waterproofing. Bitumen, plastic and rubber sheets for roofing. Method of artificial ageing by long term exposure to elevated temperature".

Etherridge, D. W., \& M, S. (1996). "Building Ventilation: Theory and Measurements." John Wiley \& Sons, New Jersey.

ETAG 004 (2009). "Guideline for European technical approval of External thermal insulation Composite systems with rendering".

Gross, D. R., \& Maas, A. (2011). "Qualitätssicherung klebemassenbasierter Verbindungs-technik für die Ausbildung der Luftdichtheitsschichten". In 6th International BUILDAIR.

Jelle, B. P. (2012). "Accelerated climate ageing of building materials, components and structures in the laboratory". Journal of Materials Science, 47(18).

Hansén, M. 2012. "Changes in airtightness after 10-20 years". Proceedings of the AIVC-TightVent international workshop, 28-29 March 2012, Brussels, Belgium. 67-75.

Hens H. (2007). "Building Physics- Heat, Air and Moisture", Wilhelm Ernst \& Sohn, Berlin. Germany.

Hens H. (2006). "The vapor diffusion resistance and air permeance of masonry and roofing systems", Building and environment 41:6, 745-755.

Kim, A., Shaw, C., Saum, D., Shaw, J. \& Colliver, D. (1986). "Seasonal variation in airtightness of two detached houses", ASTM special technical publication 904, 17-32.

Langmans, J., Klein, R., De Paepe, M., Roels, S. (2010). "Potential of wind barriers to assure airtightness of wood-frame low energy constructions". Energy and Buildings, 42 (12), 2376-2385.

Langmans, J. (2013). "Feasibility of exterior air barriers in light weight construction”. KU Leuven. Retrieved from http://bwk.kuleuven.be/bwf/PhDs/phdLangmans.

Laverge J., Delghust M., Van de Velde S., De Brauwere T., Janssens A. (2010. Airtightness assessment of newly build single family houses in Belgium. Proceedings of 5 th International BUILDAIR-Symposium "Building and Ductwork Air-tightness", Copenhagen, Denmark, pp.1- 8.

Michaux B., Loncour X., Mees C. (2012). "Assessment of the durability of Airtightness and impact on the Conception of building details", Proceedings of the AIVC-TightVent international workshop, Brussels, Belgium. 85-91.

Nordtest Method NT Build 495 (2000). "Building materials and components in the vertical position: exposure to acceleratedclimatic strains". www.nordicinnovation.net/nordtest.cfm

Tijskens, A. (2015). "Design and detailling of a prefab façade system for the thermal upgrade of an existing office building". Master thesis KU Leuven - University of Leuven, Belgium (in Dutch).

Weissmueller A. and Frédéric Delcuve F. (2013). "Evaluation of the long term durability of adhesive tapes and its substrates: Requirements and testing". Webinair AIVC TIGHTVENT. 